\title{
Greek scientists fight research shake-up
}

Instead of enjoying a tranquil summer break, Greek researchers are fighting a major reorganization that will carve up two of the country's largest research centres.

Filippos Tsalidis, head of the development ministry's office for research and technology, took the scientific community by surprise by announcing the changes, intended to promote efficiency, in the business newspaper Naftemporiki on 3 June.

He plans to reshape research institutes overseen by his ministry, turning some into single-discipline centres and uniting smaller institutes in the south and north of the country into two regional centres.

Two major multidisciplinary research centres in Athens - the National Centre for Scientific Research Demokritos and the National Hellenic Research Foundation (NHRF) - will be partly dismantled. In 2001 and 2005, panels of international experts commissioned by the Greek government judged research at these centres to be poor, although improving in parts.

Greek scientists, angry at not being consulted about the restructuring, say it will cost more than it saves, is at odds with current multidisciplinary scientific trends, and will not solve the problem of underperforming research units. The plans have sparked public demonstrations, petitions and newspaper campaigns.

The opposition socialist party has pledged to reverse the reorganization if, as opinion polls predict, it wins power in the next election in 2010.

Under Tsalidis's plan, biology and organic chemistry institutes would transfer to a new facility that would be built at the elite Alexander Fleming Biomedical Research Centre outside Athens. Demokritos would absorb the NHRF's physics and remaining chemistry institutes, leaving the NHRF focused entirely on the humanities.

"It would be better to close institutes with poor evaluations rather than move them at great cost to a top-performing institute like the Fleming and dilute its efforts," says George Thireos, head of systems biology at the new Bioacademy research centre in Athens, which is run by the Academy of Athens and is not affected by the reorganization.

In 2006, Greece spent just $0.57 \%$ of its gross domestic product on research, one of the lowest percentages in the European Union, and there have been no competitive grants awarded for more than five years. "Changes to reduce duplication and promote collaboration are definitely needed here, but not in this way," says Effie Tsilibari, head of the Demokritos Institute of Biology,

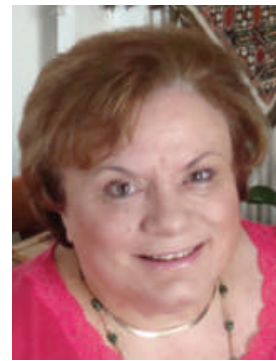

"The proposal

was rash, and it has left people paralysed."

- Effie Tsilibari which faces relocation. "The proposal was rash, and it has left people paralysed."

But George Kollias, director of the Fleming Centre, says the bombshell should be seen as an opportunity to stop talking and finally take action. "We should act even on this plan, using it to open a real discussion on how things that need to be changed can be changed," he says.

Senior Bioacademy scientists issued a statement on 30 July saying that although changes are needed, plans should be formulated through thoughtful discussions aimed at obtaining maximum consensus - and, above all, there must be greater financial investment. "Any plan that emerges without serious commitment of state funds will be doomed to failure," they warn.

Tsalidis did not respond to Nature's request for an interview. Alison Abbott

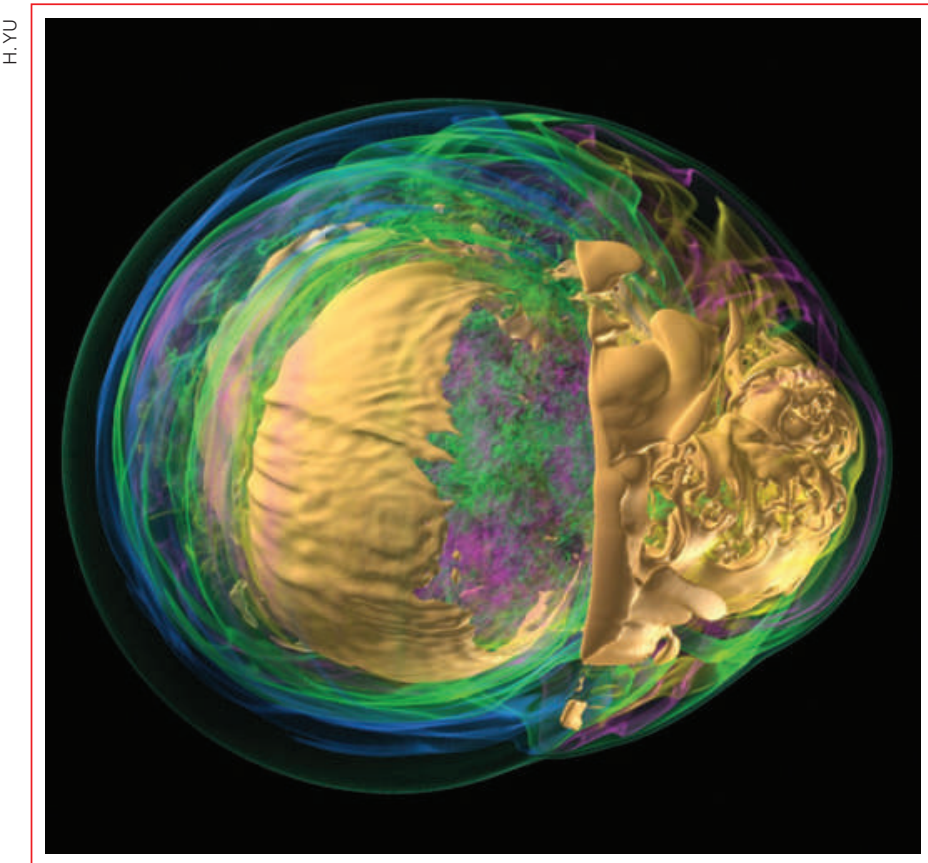

\section{SNAPSHOT The guts of a dying star}

This visualization of a simulated supernova is helping to reveal why pulsars spin so fast. Pulsars are neutron stars that emit beams of electromagnetic radiation as they whirl around many times per second a rate that astrophysicists have struggled to explain. Pulsars are thought to form in core-collapse supernovae, the explosive deaths of stars at least eight times the mass of the Sun, in which the iron core collapses in on itself.

In 2007, computer simulations suggested that the stars don't explode in perfectly smooth spheres (J. M. Blondin and A. Mezzacappa Nature 445, 58-60; 2007). This latest visualization, created by Hongfeng Yu, a computer scientist at Sandia National Laboratories in Livermore, California, shows the entropy of the gases in the dying star's core, revealing the immense swirling currents that originated as tiny perturbations (gases with the highest entropy are yellow, followed by green and then purple). The currents "spin up the proto-neutron star, just like pulling a string on an old spinning top", says Bronson Messer, an astrophysicist at Oak Ridge National Laboratory in Tennessee, who contributed to the research. The work incorporates a new visualization technique, developed at Argonne National Laboratory outside Chicago, Illinois, which runs and visualizes the simulation directly on a Blue Gene/P supercomputer.

Lizzie Buchen 